\title{
Understanding the relation between research and clinical policy: a study of clinicians' views
}

\author{
Diane Berrow, Charlotte Humphrey, John Hayward
}

Health Policy

Evaluation Unit, Department of Primary Care and Population Sciences, Royal Free Hospital School of Medicine, Rowland Hill Street, London NW3 2PF

Diane Berrow, research fellow

Charlotte Humphrey, senior lecturer in sociology

North Camden Division, Camden and lslington Health Authority, London NW1 2LJ

John Hayward, adviser in public health and primary care

Correspondence to: Ms D Berrow, Department of Primary Care and Population Sciences, Royal Free Hospital School of Medicine, Rowland Hill Street, London NW3 2PF.

Accepted for publication 14 May 1997

\begin{abstract}
Objectives-To describe the relation between research evidence and local obstetric unit policy for specific areas of care and to explore clinicians' views about the reasons for any discrepancies identified. Design-An independent evaluation of a project undertaken by a district maternity services liaison committee (MSLC) to promote evidence based maternity care in specific areas of care. The evaluation involved a combination of qualitative methodologies including documentary analysis, non-participant observation, semi-structured interviews, and self com-
\end{abstract} pleted open ended questionnaires.

Setting-One English health district with three obstetric units.

Main measures-Congruence between unit policies and research evidence in specific areas of care. Views expressed by unit staff concerning the reasons for any discrepancies identified. Consistency between staff views within and between units. Unit attitudes to modification of discrepant policies and details of any subsequent changes made.

Results-Of the 12 unit policies considered, seven were consistent with the research evidence. In all cases in which unit policy did not reflect the evidence, provider unit staff thought that the differences were justified. In several cases there were substantive differences of view between staff in different units. No differences of view were expressed between staff in the same unit. There were three different types of concern about the research evidence and the problems of using it as a basis for deciding unit policy. These were: concerns about the adequacy or completeness of the evidence; concerns about the applicability of the evidence in the local setting; and concerns about local capacity to act on the evidence. At the time of the project, none of the units expressed any intention of modifying the policies under discussion. Subsequently, two of them did make changes of this sort.

Conclusion-The results suggest the need for further research to ascertain what factors may produce such varying assessments of the validity and adequacy of particular sets of research findings as were found between clinicians in this study and to understand what considera- tions other than views about evidence may affect decisions to alter clinical policy. Implications-When clinicians have clear reasons for not following research evidence, two contrasting responses are possible. One is to take the view that the clinicians are mistaken, and seek to change their attitudes or persuade them to change their behaviour regardless of their views. An alternative response is to accept that the concerns they express may be legitimate and consider how their doubts may be addressed. The challenge is to recognise which response is preferable in any particular situation.

(Quality in Health Care 1997;6:181-186)

Keywords: clinical policy; clinicians' views; obstetric units

There is growing recognition of a large gap between research evidence and clinical policy and practice and possible reasons for the existence of this gap have been identified. These include lack of access to the research evidence or insufficient skills to appraise it on the part of clinicians, and organisational, attitudinal, and cultural barriers to acceptance and adoption. ${ }^{1-3}$ A wide range of research, training, and dissemination initiatives have been developed at both national and local levels to deal with these obstacles. ${ }^{45}$

It is also acknowledged that in some cases there may be good reasons for deciding that the evidence in respect of a specific intervention does not apply to a particular patient or patient population. ${ }^{6}$ Even the most enthusiastic advocates of evidence based medicine are keen to emphasise that evidence on its ownhowever robust-cannot provide a simple blueprint for what should happen in practice. Rather, clinical decisions should be based on the "best available" evidence used in concert with individual clinical expertise. ${ }^{89}$ In areas where the evidence is inconclusive, incomplete, or based on less than "gold standard" methodologies clinical judgement will inevitably play a greater part. ${ }^{10}$

Thus policy or practice at a local level may be at odds with the research evidence for various reasons, some quite justifiable, others probably less so. If efforts to increase the appropriateness of clinical interventions are to be appropriately focused and successful, the first step to deciding whether change is needed or what action might be appropriate in any particular case is to find out why the discrepancies exist. An 
Setting

The Effective Care Project was set up by the district maternity services liaison committee (MSLC) of one English health district.

\section{Aim}

The aim of the project was to ensure that policy and practice in specific areas of care in the three local obstetric units were based on authoritative research evidence.

\section{Process}

Four interventions were chosen from the Cochrane Pregnancy and Childbirth Database $(C C P C)^{11}$ to act as a focus for the project in the first year. This database comprises a comprehensive collection of systematic reviews of randomised controlled trials of about 600 interventions relating to pregnancy and childbirth. The four interventions chosen were corticosteroids in potential preterm delivery, prophylactic antibiotics for caesarean section; management of perineal repair; and external cephalic version (ECV) at term for breech presentation. The interventions were chosen on the basis that the evidence seemed robust. All four had also been described by the Royal College of Obstetricians and Gynaecologists as effective procedures for audit. $^{12}$

A subgroup of the MSLC was set up to take the project forward. For each of the four interventions, the subgroup sent copies of the relevant database reviews to the three provider units. This was followed by a structured meeting in each unit between members of the subgroup and consultant, midwifery, and service management representatives from the unit. At each meeting, unit staff were invited to provide details of their policy for the intervention in question. Policy was taken to mean written guidelines or, in the absence of these, any consensus which was thought to exist among staff regarding the intervention. This was followed by discussion of the reasoning behind any differences between unit policy and the research findings and consideration of what steps might be taken to ensure that policy was adequately research based. After the meetings, the subgroup reported back to the MSLC with an overview of policy in the three units and the MSLC decided how work on each intervention should be taken forward. By the end of one year, meetings had taken place in all three units for each of the four interventions.

\section{Aims of the independent evaluation}

Funding was obtained by the health authority for an independent evaluation of the Effective Care Project. The purpose of the evaluation was to assess the feasibility of the approach and its acceptability to participants. The findings were intended to inform the MSLC's reappraisal of the project at the end of the initial year.

Box 1 The effective care project and the aims of the independent evaluation. obvious starting point is to ask for explanation from the clinicians responsible for providing care.

In this paper we describe the relation between research evidence and obstetric unit policies for specific aspects of care in one English health district and explore local clinicians' views about the reasons for the discrepancies found. The data presented were collected during the course of an independent evaluation conducted by two of us ( $\mathrm{CH}$ and $\mathrm{DB}$ ) of a project (the Effective Care Project) set up by the local maternity services liaison group (MSLC) $^{\star}$ to promote evidence based maternity care.

Box 1 shows a description of the project in question (the Effective Care Project) and of the objectives of the evaluation.

\section{Methods of evaluation}

The evaluation involved a combination of qualitative methodologies including documentary analysis, non-participant observation, semistructured interviews, and self completed open ended questionnaires. The evaluators had access to all minutes, reports, and other relevant documents used or generated by the project. They observed all nine project subgroup planning meetings, all 12 meetings between the subgroup and individual provider units, and all 12 meetings of the full MSLC which occurred during the evaluation year. The proceedings of these meetings were recorded verbatim by both evaluators and notes crosschecked for accuracy and completeness.

All members of the subgroup $(n=6)$ and all provider unit staff $(n=19)$ who participated in the meetings with the subgroup were interviewed (or in three cases when interviews could not be arranged, asked to complete questionnaires) after the first round of meetings and again towards the end of the evaluation year. The interviews were semi-structured, were all conducted by one of the evaluators (DB), and lasted from 30 to 45 minutes. In the interviews, respondents were asked for their views on the appropriateness of the project aims and approach and the costs and benefits of the work programme. When differences were identified between unit policy and the research evidence relating to the interventions discussed during the project, respondents were also invited to elaborate on the reasons for these differences. Notes were taken during the interviews and written up immediately afterwards.

For the purposes of this paper, all documents used or generated by the project subgroup, evaluators' notes from observation at meetings, and interviews with participants were gathered together and searched for references to: the research evidence concerning the four interventions; unit policy relating to the four interventions; and the relation between

ॠAn MSLC is a multidisciplinary committee set up and run by either a health authority or provider unit and draws membership from the local health authority, obstetric units, and user organisations. In most health districts MSLCs provide a forum for professionals and users to contribute to the planning and development of local maternity services. 
Table 1 Conclusions of the CCPC database reviews and existing unit policies for the four interventions

\begin{tabular}{|c|c|c|}
\hline Intervention & CCPC conclusions & Unit policies* \\
\hline $\begin{array}{l}\text { Corticosteroids before } \\
\text { preterm delivery }\end{array}$ & $\begin{array}{l}\text { Giving corticosteroids to } \\
\text { women who are expected to } \\
\text { deliver preterm can be } \\
\text { expected to reduce neonatal } \\
\text { morbidity and mortality } \\
\text { (review 02955) }\end{array}$ & $\begin{array}{l}\text { Policy in all three units ( } A, B \text {, } \\
\text { and } C \text { ) was to give } \\
\text { corticosteroids routinely to } \\
\text { pregnant women when there is } \\
\text { a risk of preterm delivery }\end{array}$ \\
\hline $\begin{array}{l}\text { Prophylactic antibiotics in } \\
\text { caesarean section }\end{array}$ & $\begin{array}{l}\text { Giving prophylactic antibiotics } \\
\text { to women undergoing } \\
\text { emergency or elective } \\
\text { caesarean section can be } \\
\text { expected to result in a } \\
\text { considerable reduction in } \\
\text { postoperative infectious } \\
\text { morbidity (reviews } 03690 \text { and } \\
03775 \text { ) }\end{array}$ & $\begin{array}{l}\text { Policy in two units (A and B) } \\
\text { was to give antibiotics } \\
\text { routinely to women } \\
\text { undergoing caesarean section. } \\
\text { Policy in unit C was to give } \\
\text { antibiotics selectively to } \\
\text { women judged to be at } \\
\text { particular risk, but not to } \\
\text { offer them routinely }\end{array}$ \\
\hline $\begin{array}{l}\text { Management of perineal } \\
\text { repair after vaginal delivery }\end{array}$ & $\begin{array}{l}\text { Polyglycolic acid sutures } \\
\text { (Dexon or Vicryl) are } \\
\text { preferable to silk as they are } \\
\text { associated with less pain in the } \\
\text { short term and lower risk of } \\
\text { resuturing in the longer term } \\
\text { (for both perineal skin and } \\
\text { deeper tissues). Absorbable } \\
\text { materials are associated with } \\
\text { less pain in the short term } \\
\text { than non-absorbable } \\
\text { materials. Of the two most } \\
\text { commonly used absorbable } \\
\text { materials, polyglycolic acid is } \\
\text { preferable to catgut (reviews } \\
03794 \text { and } 03253 \text { ) }\end{array}$ & $\begin{array}{l}\text { None of the units }(\dot{A}, \mathbf{B}, \text { or } \\
\text { C) had explicit policies on } \\
\text { the suture to be used }\end{array}$ \\
\hline $\begin{array}{l}\text { External cephalic version } \\
(\mathrm{ECV}) \text { at term for breech } \\
\text { presentation }\end{array}$ & $\begin{array}{l}\text { ECV at term is relatively safe } \\
\text { and can be expected to reduce } \\
\text { the number of breech } \\
\text { deliveries and caesarean } \\
\text { sections. The numbers studied } \\
\text { are insufficient to give a } \\
\text { precise estimate of the } \\
\text { perinatal risks (review } 03087 \text { ) }\end{array}$ & $\begin{array}{l}\text { Policy in two units (A and B) } \\
\text { was to offer ECV to all eligible } \\
\text { women with breech } \\
\text { presentation at term. In unit } \\
\text { C ECV was not offered } \\
\text { routinely, but was } \\
\text { sometimes provided if a } \\
\text { woman specifically } \\
\text { requested it }\end{array}$ \\
\hline
\end{tabular}

${ }^{\star}$ Discrepancies between research evidence and unit policy are marked in bold.

evidence and policy. Relevant information from all the sources above was extracted and listed by intervention and by unit. The data for each intervention and each unit were then compared to establish whether unit policies were congruent or at odds with the research evidence and, if the second, how they differed. Views expressed by unit staff concerning the reasons for any discrepancies between the research evidence and unit policy were examined for consistency within and between units. Finally, the content of the arguments presented by staff was analysed to generate a typology of reasons for not acting in accordance with the evidence. To ensure reliability, the two evaluators each analysed the data independently and results were then compared. Both generated very similar systems of categorisation, although these were initially described in slightly different terms.

The reliability of the information concerning the views of the unit staff who participated in the project was checked in two ways. Firstly, as part of the project process all written reports prepared by the project subgroup of its meetings with unit staff were sent to the units involved for verification and amendment before being presented to the MSLC. Secondly, a report on the evaluation findings, including staff views on the relation between evidence and policy, was sent to all those who had been involved in the project with a request for feedback and was also discussed at a meeting of the
MSLC. From the comments received, it seemed that staff thought that their views were reported accurately.

\section{Results}

Twelve aspects of unit policy were explored by the Effective Care Project. In seven cases, the units had written or verbal policies which were congruent with the research evidence. In five cases, units either had no explicit policy or had policies which were at odds with the research evidence (table). In all cases where unit policy did not reflect the conclusions of the database reviews, provider unit staff considered that they had good grounds for not acting in accordance with the CCPC recommendations. Explanations for unit policy were consistently presented as representing the agreed views of the unit as a whole, rather than those of individual staff and there were no differences of view expressed between staff within the same unit. With regard to suture materials for perineal repair - the one area studied where none of the units had policies which accorded with the evidence-staff in all three units concurred in their views as to why this was so.

Analysis of the arguments presented by staff presented three distinct types of concern about research evidence and the problems of using it as a basis for deciding unit policy.

\section{CONCERNS ABOUT THE ADEQUACY OR}

COMPLETENESS OF THE EVIDENCE

For all the interventions apart from corticosteroids in preterm delivery, at least one unit had doubts about the adequacy of the evidence. The concern was not so much about what the trial findings in question showed, but about the interpretation of these findings in the absence of adequate information about other issues which those trials did not consider, such as longer term outcomes or the interaction between different elements of care.

\section{Example}

Staff in unit C (which did not offer antibiotics routinely to women undergoing caesarean section) were concerned that the evidence in favour of prophylactic antibiotics for caesarean section all came from hospital based trials. They thought that the database contained inadequate evidence that prophylactic antibiotics actually prevented infection, as opposed to merely delaying its appearance until after the time when the women were discharged from hospital.

\section{Example}

Staff in all three units were concerned about the inconclusiveness of the evidence regarding the impact on long term outcomes of the different suture materials in current use for perineal repair, although they accepted that the trial data show Vicryl to be associated with less pain in the short term (up to 12 weeks after delivery). It was also pointed out that the outcome of perineal repair depends on the interaction of several different components of clinical care including the material used, 
suturing technique, and skill of different operators. The importance of this interplay had not been considered in the trials.

\section{CONCERNS ABOUT THE APPLICABILITY OF THE} EVIDENCE IN THE LOCAL SETTING

For two of the interventions studied (prophylactic antibiotics for caesarean section and ECV at term for breech delivery), contextual factors were thought by one of the units (unit C) to have a moderating influence on the perceived applicability of the research evidence. Staff argued that the risks and benefits of any particular intervention may be influenced by local circumstances, such that an intervention that does more good than harm in one setting may have the reverse effect in another. Similarly the balance of benefit between different treatment options for a particular problem may vary in different environments.

\section{Example}

Staff in unit C (which did not offer antibiotics routinely to women undergoing caesarean section) pointed out that most of the trials of this intervention had been carried out in countries where the clinical procedures and the organisation of care for women undergoing caesarean section were different from those in the United Kingdom. They argued that the findings of trials carried out in such settings could not automatically be assumed to be applicable in this country. They were also concerned that any unnecessary use of antibiotics should be avoided, because of the dangers of promoting drug resistant bacteria (which were a significant problem locally), and thought that the small gains associated with the use of prophylactic antibiotics in maternity units where infection rates were already low would be insufficient to justify the risk incurred.

\section{Example}

Staff in unit C (where ECV was not routinely offered to all eligible women with breech presentation at term) pointed out that most of the trials of ECV were carried out in countries where the patient population, social environment, and organisation of care were very different from those that pertained locally. They considered that, for anatomical reasons to do with pelvis shape, ECV would be less likely to be effective in turning a baby than the trial data indicated. They also thought that, in the local setting, the alternative management strategies of vaginal breech delivery or elective caesarean section were safer than they might be elsewhere. For both these reasons they thought that the risks attached to ECV were likely to outweigh the potential benefits.

\section{CONCERNS ABOUT LOCAL CAPACITY TO ACT ON THE EVIDENCE}

For two of the interventions studied (suture materials for perineal repair and ECV for breech presentation at term) concern was expressed by one or more units about the idea that policy at a local level could be based on the conclusions of research findings alone, without taking account of local capacity to carry out the intervention in question both safely and effectively.

\section{Example}

Staff in all three units were informally aware that the skills and techniques of those involved in carrying out perineal repair within their units varied widely, as did their experience of using different suture materials. It was widely agreed that it would be inappropriate in the short term to move towards exclusive use of any one material without a thorough appraisal of what was actually going on within the unit and what additional training might be required.

\section{Example}

The policy of offering ECV to women with breech presentation at term was a very recent development in unit $B$, which had only become possible when a clinician who had been trained in undertaking this intervention joined the unit. Unless and until other staff developed this competence, the option of ECV was contingent on this clinician being available to perform it.

At the time of the meetings between the units and the project subgroup, none of the units expressed any plans to modify their policies on the interventions under study to make them more congruent with the research evidence. Subsequently, however, two units made changes of this sort. In unit A, after a review of actual practice within the unit with regard to perineal repair, a written policy promoting the use of Vicryl as the "preferred" material for suturing was instituted and steps were being taken to ensure that all staff had the necessary competence to use Vicryl effectively. Unit C conducted a review of its policy on breech presentation at term and decided to offer ECV, to which end it produced a written protocol. The review involved taking advice from the Royal College of Obstetricians and Gynaecologists, ascertaining what was happening in other teaching units beyond the district (many had recently begun to offer ECV), and discussing the issues with colleagues in those units.

As both of these changes took place after the evaluation was concluded, no direct information was obtained as to what exactly led the two units to make these modifications to their policies. In neither case had any new research data become available to answer the fundamental concerns they had expressed earlier about the adequacy or applicability of the research evidence for the interventions in question. What did happen was that both units were stimulated (possibly by their involvement in the project) to obtain more systematic information about actual practice-either their own or that of colleagues in other units-and chose to look critically at what they found. Perhaps the voluntary, practical focus on what was happening in the real world contributed in some way to the units' reassessments. 


\section{Discussion}

The findings presented here were obtained during the evaluation of a local project involving only four interventions and a few clinicians in three obstetric units. No claims can be made about the representative nature of the units in this study, nor about the generalisability of the types of concerns about research evidence expressed by the staff involved. It may well be that further studies of other interventions with different clinicians or specialties would identify additional types of explanation for maintaining unit policies that are out of line with the research evidence. It should also be noted that the focus of the study was on formal unit policies, not on actual practice. No evidence has been presented as to how far policies were actually being followed.

Despite these limitations, the findings help not only to explain what was going on in the local situation, but also to develop a more systematic understanding of how clinicians view research evidence and how these views may impact on unit policy and to identify areas for further research. For example, the findings show considerable variation between different units in the acceptance of research evidence. For two of the interventions discussed during the project, staff in one of the units studied expressed major concerns about the research evidence, whereas those in the other two units fully accepted the research findings. In one case, these contrasting responses reflected varying assessments of the local applicability of the research in the context of particular local differences between units. In the other, however, there was disagreement over the adequacy of the research evidence itself. There is a need for further study to ascertain what factors may produce such varying assessments between clinicians of the validity and adequacy of particular sets of research findings.

By contrast with the variation between units, staff within each unit expressed a complete consensus of views. This apparent consistency needs to be regarded with some caution, as it may well have been encouraged by the fact that the project focused explicitly on unit policy. In the circumstances, it is possible that staff within units chose to minimise any differences of opinion which may have existed to present a united response. Anecdotal information obtained by the evaluators through contact with other staff in the study units indicates that in some cases there may have been more variation of opinion and flexibility in interpreting policy than is apparent from the study findings. Again, more work is needed to explore the relation between the views of clinical staff within provider units and to understand how agreement is reached on what is presented as "the unit's view".

The findings from this study also highlight the complexity of the relation between attitudes and behaviour in this area. It is already well recognised that acceptance of research evidence is not, in itself, sufficient to change practice. The decisions of two of the study units to modify their policies, despite the fact that their concerns about the evidence re- mained apparently unanswered, indicate that acceptance of the evidence may not always be a necessary condition for changing practice. Such findings add weight to the argument already put by Dopson et $a{ }^{\beta}$ that further research is urgently needed to increase understanding of the interplay between knowledge, attitudes, and cultural, organisational, and other factors in affecting changes in professional behaviour.

We began this paper by suggesting that knowledge of clinicians' views about the relation between research evidence and unit policy or practice might be of value in deciding what, if anything, needed to be done in any particular case in which discrepancies were identified. The default assumption of those concerned to increase the appropriateness of clinical interventions by expansion of evidence based practice is that, if a gap is found, it ought to be closed. In this study, in all cases in which unit policies did not reflect the conclusions of the database reviews, provider unit staff gave clear justifications for the differences. In some cases, they accepted that there were organisational barriers to change (particularly to do with shortage of practical clinical skills) which could, with benefit, be resolved. They did not, however, regard themselves as lacking information about the research evidence or the skills to appraise it.

In such a situation, two contrasting responses are possible for those who still wish to see change occur. One is to take the view that the clinicians are mistaken and either seek to change their attitudes or persuade them to change their behaviour regardless of their views, by, for example, increasing the incentives to adopt the policies required or introducing penalties for not doing so. As our findings have shown, change can occur in the absence of conviction (although there was no evidence in this case of either pressure or incentives being applied). An alternative response is to accept that the concerns expressed by clinicians may be legitimate and consider how their doubts may be addressed. This may involve commissioning further basic research or finding out more about the circumstances and problems thought to prevent the research findings being applicable at local level. Such activities may take both time and additional resources.

The first approach may work, but it may not always maximise goodwill. The second is likely to involve delay, for the acceptance of a genuine element of doubt provides sceptical clinicians with justification for maintaining the status quo. However, in the long run it might prove worthwhile in gaining positive support. The challenge is to recognise which response is preferable in any particular situation, as neither is likely always to be appropriate.

We thank all members of the MSLC and unit staff who participated in the project. The evaluation was funded by North Thames Regional Health Authority.

1 Deykin D, Haines A. Promoting the use of research findings. Chapter 15. In: Peckham M, Smith R, eds. Scientific basis of health services. London: BMJ Publishing, 1996.

2 Harrison S. Knowledge into practice: What's the problem? Harrison S. Knowledge into practice: What's the
fournal of Management in Medicine 1994;8:9-16. 
3 Dopson S, Mant J, Hicks N. Getting research into practice: facing the issues. Fournal of Management in Medicine 1994; 8;6:4-12.

4 Advisory Group to the Central Research and Development Committee. Priorities for the evaluation of methods of implementation of research findings. London: Department of Health, 1995.

5 Haines A. The science of perpetual change. $\mathrm{Br} \mathcal{F}$ Gen Pract 1996;46:115-9.

6 Rothwell PM. Can overall results of clinical trials be applied to all patients? Lancet 1995;345:1616-9.

7 Grimshaw J, Russell I. Achieving health gain through clinical guid Jines I: Developing scientifically valid guidelines. Quality in Health Care 1993;2:243-8.
8 Sackett DL, Rosenberg WC, Muir Gray JA, Haynes RB, Richardson WS. Evidence based medicine: what it is and Richardson WS. Evidence based medicine: what it is and what it isn't. BMf 1996,312.71-2.

9 Thompson SG, Pocock SJ. Can meta-analyses be trusted? Lancet 1991;338:1127-30.

10 Naylor CD. Grey zones of clinical practice: some limits to evidence-based medicine. Lancet 1995;345:840-2.

11 Neilson, JP, Crowther CA, Hodnett ED, Hofmeyer GJ, Keirse MJ, Daley L, et al, eds. Pregnancy and childbirth module, Cochrane database of systematic reviews. Oxford: Cochrane updates on disk, update software, 1995.

12 Royal College of Obstetricians and Gynaecologists. Effective procedures in obstetrics suitable for audit. London: RCOG, 1993. 